Volume 9 - $2019 \mid$ n. 3

\title{
Repercussões do FUNDEB em Municípios Mineiros: aportes para a discussão sobre um FUNDEB permanente
}

\author{
Daniel Santos Braga \\ Centro Universitário Newton Paiva, Belo Horizonte/MG - Brasil \\ Universidade Federal de Minas Gerais (UFMG), Belo Horizonte/MG - Brasil \\ Débora Cristina Alves da Silva \\ Universidade Federal de Minas Gerais (UFMG), Belo Horizonte/MG - Brasil
}

\begin{abstract}
Resumo $^{1}$
O artigo analisa a execução do Fundo de Manutenção e Desenvolvimento da Educação Básica (FUNDEB) nas redes municipais de educação de Minas Gerais no ano de 2017. Investiga também desigualdades na federação quanto a investimentos públicos mais equitativos em manutenção e desenvolvimento do ensino (MDE). A fonte de pesquisa foi a base de dados Finanças do Brasil (FINBRA), disponibilizada pela Secretária do Tesouro Nacional (STN). O objetivo do estudo foi mensurar e comparar a capacidade institucional de atendimento em educação dos municípios mineiros em um cenário com e sem o FUNDEB. Os achados da investigação indicam que, apesar de o FUNDEB ser uma importante política redistributiva e redutora de desigualdades, em Minas Gerais, no que diz respeito à distribuição de seus recursos em um cenário sem o fundo de financiamento do FUNDEB, o custo alunoano já era atingido pelos municípios.
\end{abstract}

Palavras-chave: Financiamento da Educação. FUNDEB. Desigualdades. Gestão Educacional.

\section{FUNDEB Repercussions in Minas Gerais Municipalities:}

contributions to a discussion on a permanent FUNDEB

\begin{abstract}
This article analyzes the implementation of the Basic Education Development Fund (FUNDEB) in municipalities of Minas Gerais state, Brazil, in 2017. It is also intended to investigate inequalities in the federation concerning public investments in the maintenance and development of education (MDE). The research source was the Finanças do Brasil (FINBRA) database made available by the National Treasury Secretary. The aim of the study is to measure and compare the institutional capacity of attendance in education of Minas Gerais municipalities in a scenario with and without FUNDEB. The results of the research indicate that although FUNDEB is an important redistributive policy, also reducing inequalities, in Minas Gerais, regarding the resources distribution in a scenario without the funding from FUNDEB, the student-year cost had already been reached by the municipalities.
\end{abstract}

Keywords: Financing of Education. FUNDEB. Inequalities. Educational Management.

\footnotetext{
Este artigo é parte da pesquisa Desigualdades educacionais: mapas, trajetórias e medidas, desenvolvida pelo grupo Política e Administração de Sistemas Educacionais (PASE) no âmbito do Programa de Pós-Graduação em Educação da Faculdade de Educação da Universidade Federal de Minas Gerais (PPGE/FaE/UFMG), e foi financiado com recursos do Conselho Nacional de Desenvolvimento Científico e Tecnológico (CNPq) e do Fundo de Amparo à Pesquisa do Estado de Minas Gerais (FAPEMIG).
} 
Repercussões do FUNDEB em Municípios Mineiros

\section{Introdução}

A aprovação da Constituição Federal de 1988 (CF/88) representa um marco importante e elucidativo, pois, além de romper com um regime autoritário, apresenta inovações, dentre as quais a alteração da figura dos municípios. A partir da publicação da Carta Magna, os municípios são reconhecidos como entes federados, junto à União, estados e Distrito Federal, e assumem uma condição de autonomia, acumulando outros e novos encargos, dentre eles, a promulgação de suas próprias leis orgânicas (ABRUCIO, 2005). Ainda no tocante às incumbências da esfera municipal, no que compete ao financiamento educacional, a Carta Magna estabelece a responsabilização dos municípios, juntamente com os estados e Distrito Federal, de destinar, no mínimo, 25\% dos recursos financeiros resultantes dos impostos, incluindo transferências, à manutenção e desenvolvimento do ensino.

Com esse novo papel dos municípios como entes federados, assistiu-se, nas últimas décadas, a uma intensa municipalização da educação brasileira. A municipalização é um processo no qual há a transferência de matrículas e responsabilidades dos estados para os municípios. Ademais, a delegação de responsabilidades pode se suceder de forma a esboçarse em ações que indiquem o reconhecimento da autonomia do ente federado ou significar apenas a atribuição de novos encargos à instância municipal (OLIVEIRA, 2003). Estudos como o de Oliveira et al. (1999), que se debruçam sobre a descentralização do ensino brasileiro, visualizam as legislações da década de 1990 como marcos, por dar contornos importantes ao sistema educacional nos anos posteriores à promulgação da CF/88: na oferta, na gestão e no financiamento.

Desse conjunto de leis, merecem ser salientadas as Diretrizes e Bases da Educação Nacional (LDB), instituídas pela Lei 9.394/1996, e as legislações que instituem e regulamentam o Fundo de Manutenção e Desenvolvimento do Ensino Fundamental e de Valorização do Magistério (FUNDEF), a Emenda Constitucional $n^{\circ} 14 / 96$ e a Lei $n^{\circ}$ 9.424/96, respectivamente. Tal fundo, conforme apontam as investigações de Abreu (2003) e Arelaro (2007), foi decisivo no processo de municipalização do ensino fundamental e da educação infantil no País. Durante sua vigência, os recursos foram destinados exclusivamente ao ensino fundamental, de acordo com o número de matrículas ofertado por cada dependência administrativa. Tal situação foi alterada apenas no ano de 2007 , com a substituição do FUNDEF pelo Fundo de Manutenção e Desenvolvimento da Educação Básica e de Valorização dos Profissionais da Educação (FUNDEB), Lei 11.494/2007, o qual amplia a aplicação dos recursos do fundo para as outras etapas da educação básica, a educação infantil e ensino médio e outras modalidades do ensino, como a Educação de Jovens e Adultos (EJA).

O artigo 48 da lei do FUNDEB definiu o final da vigência do fundo para dezembro de 2020. Porém, com a recente aprovação do Plano Nacional de Educação (PNE), em 2014 (Lei 13.005), começaram a surgir propostas para que o fundo se torne permanente (PEC 191/12, arquivada em 2015 e a PEC 15/15, que atualmente tramita no Congresso Nacional). Essa mudança constitucional se justificaria, uma vez que o eventual encerramento do fundo poderia prejudicar o cumprimento das metas previstas no PNE. Se justificaria também uma vez que o FUNDEB tinha uma importante função de corrigir desigualdades econômicas, garantindo recursos mínimos por aluno. Frente a essa conjuntura, emerge o objeto deste trabalho, que é 
entender a operacionalização do FUNDEB e as suas implicações nas redes municipais de Minas Gerais, no que se refere à composição do total de recursos destinados à educação, assim como as perdas e ganhos desses entes federados com o fundo.

O objetivo deste artigo é contribuir com os debates sobre a proposta de se tornar o FUNDEB um fundo permanente, com presença na carta constitucional, assim como se avaliar os limites e possibilidades desse fundo como política redistributiva e sua capacidade de reduzir desigualdades regionais. Para isso, está dividido em duas partes. Na primeira seção, foi feita uma descrição histórica e normativa das políticas de fundo; e da transição do FUNDEF para FUNDEB. Na segunda parte, realizou-se uma análise da relação entre a arrecadação dos municípios e seus recursos destinados à educação em 2017.

\section{Do FUNDEF ao FUNDEB: perspectivas e avanços}

O direito social à educação, previsto no artigo $208^{\circ}$ da CF/88 e no artigo $4^{\circ}$ da LDB, deverá ser garantido assegurando padrões mínimos de qualidade de ensino, definidos como a variedade e quantidade mínimas, por aluno, de insumos indispensáveis ao desenvolvimento do processo de ensino-aprendizagem. Dentre estes “insumos indispensáveis", estão espaços físicos, materiais didáticos, equipe pedagógica e professores bem formados e remunerados, com planos de carreira, dentre outros. Portanto, para que se existam tais insumos, é necessário que se tenham recursos suficientes para assegurá-los. Em outras palavras, um sistema de financiamento da educação.

Por financiamento da educação entende-se o campo de estudos que analisa as fontes de recursos destinadas à educação, assim como o padrão de gastos desses recursos (PINTO, 2000). Nesse sentido, o Financiamento Público é um tipo de política pública e social, uma vez que representa um conjunto sistemático de ações e procedimentos inter-relacionados, publicamente adotados pelos governos dos entes federados com o fim de assegurar o direito social da educação (REIS, 2010; FLEURY, 2010).

$\mathrm{O}$ atual modelo de financiamento da educação no Brasil tem como base as discussões sociais e políticas que se deram no País durante o processo de reabertura no final da década de 1970 e início da década seguinte. Nesse período, foi aprovada a Emenda Constitucional $\mathrm{n}^{\circ} 24$ de 01 de dezembro de 1983 (EC 24/83), também chamada "Emenda Calmon", em referência a seu autor, o Senador João Calmon, que reestabeleceu a vinculação de parte das receitas de impostos da União e dos Estados, além de reafirmar a vinculação municipal, para a educação. Essa vinculação se consolida na CF/88, no artigo 212, com a garantia do financiamento público da educação através de vinculação de receitas de impostos, mantendo a mesma fórmula da "Emenda Calmon", com revisão dos percentuais, de 12\% na EC 24/83 para $18 \%$ na nova Carta. Os Estados e municípios vinculariam $25 \%$ de suas receitas conforme o texto constitucional

A receita dos impostos consistiria então na grande fonte de recursos de investimento nos diversos sistemas educacionais do Brasil. É importante registrar que a arrecadação dos impostos no País é feita de maneira descentralizada, sendo que cada nível de administração pública se responsabiliza por abranger uma determinada área, constituindo sua receita e complementando-a com contribuições fiscais e econômicas (PINTO, 2000). Assim, os arranjos federativos incidem diretamente na capacidade de financiamento da educação. Segundo Pinto (2000), esse arranjo pode ser percebido nas competências dos entes em 
Repercussões do FUNDEB em Municípios Mineiros

relação a sua capacidade de arrecadação. A quantidade de impostos federais é bastante representativa, porém, devido às suas competências constitucionais, acaba realizando uma contribuição relativamente pequena para a educação básica. Em contrapartida, os municípios, responsáveis pela oferta de parcela significativa da educação básica, apresentam baixo poder de arrecadação, comprometendo a sua capacidade de atendimento (PINTO, 2000).

A despeito dessa distorção, a vinculação de receitas possibilitou uma "estabilidade relativa" do Financiamento Público da Educação. Essa relatividade se dá uma vez que, apesar de a receita de impostos ser a maior fonte de recursos para a educação, e ser um recurso "fixo", seu montante está condicionado às variações macroeconômicas (FARENZENA, 2006). Apesar dessa relativa estabilidade, a desigualdade entre os entes se tornou bastante evidente, uma vez que a capacidade de cada ente em arrecadar passou a ser diretamente responsável pelo montante de recursos a ser gasto em educação. De acordo com levantamentos feitos por Negri (1997), a composição do total do montante destinado para a educação na primeira metade da década de 1990 se configurava com os impostos representando $89 \%$ do total.

Devido às grandes disparidades econômicas regionais no País, passou-se a discutir formas de minimizar as desigualdades entre os entes federativos (ARELARO, 2007). No contexto dos debates sobre a regulamentação dos artigos de educação, prevista na Constituição, foi aprovada a Emenda Constitucional $n^{\circ}$ 14, de 24 de dezembro de 1996 (EC 14/96). Essa emenda deu nova redação para o art. 60 do Ato das Disposições Constitucionais Transitórias (ADCT), que passou a tratar da criação de um fundo para a manutenção e desenvolvimento do ensino e de valorização de seus profissionais:

\footnotetext{
I - a distribuição dos recursos e de responsabilidades entre o Distrito Federal, os Estados e seus Municípios é assegurada mediante a criação, no âmbito de cada Estado e do Distrito Federal, de um Fundo de Manutenção e Desenvolvimento do Ensino Fundamental e de Valorização do Magistério - FUNDEF, de natureza contábil;

II - os Fundos referidos no inciso I do caput deste artigo serão constituídos [...] e distribuídos entre cada Estado e seus Municípios, proporcionalmente ao número de alunos das diversas etapas e modalidades da educação básica presencial, matriculados nas respectivas redes, nos respectivos âmbitos de atuação prioritária estabelecidos nos $\S \S 2^{\circ}$ e $3^{\circ}$ do art. 211 da Constituição Federal (BRASIL, 1988).
}

Como resultado desses dois instrumentos, a EC14/96 e os ADCT com a nova redação, o FUNDEF é criado e regulamentado a partir da Lei 9.424 de 24 de dezembro de 1996, tornando-a referência jurídica para o financiamento público da educação brasileira. Sua existência estava prevista pelo prazo de 10 anos e sua regulamentação se deu com o Decreto $\mathrm{n}^{\circ} 2.264$, de 27 de junho de 1997. O objetivo principal do FUNDEF era resolver as distorções e disparidades regionais da educação, redistribuindo equiparativamente os recursos, ampliando-os, além de possibilitar a valorização do magistério.

Segundo a legislação, o FUNDEF seria constituído pela subvinculação de transferências constitucionais. Para estados e Distrito Federal, o fundo receberia $15 \%$ dos recursos do Fundo de Participação dos Estados (FPE), da Cota Estadual do ICMS e da Cota Estadual do IPIExportação. Para os municípios, os recursos subvinculados seriam advindos de $15 \%$ do Fundo de Participação dos Municípios (FPM), da Cota Municipal do ICMS e da Cota Municipal do IPI-Exportação. Incluem-se no cálculo do FUNDEF as compensações referentes às perdas ocasionadas pela Lei Complementar 87/96 (Lei Kandir). A União não contribuiria para a 
formação do fundo, ficando com a função de complementação caso o valor do FUNDEF por aluno no estado ficasse inferior ao valor mínimo nacional estipulado anualmente (fixado em $\mathrm{R} \$ 300,00$ em 1997 pela Lei 9.424/96). Dada a limitada capacidade orçamentária dos municípios brasileiros, estes entes se tornam extremamente dependentes dos recursos do FUNDEF. Como o montante de recursos recebidos dependeria do número de alunos na rede, o fundo acabou por induzir um intenso processo de municipalização de matrículas nas redes (ARELARO, 2007).

Ao final do período de vigência do FUNDEF, a avaliação era a de que o fundo não havia conseguido superar os grandes desafios da educação brasileira (ARELARO, 2004). Os anos finais do FUNDEF foram marcados por discussões acerca da prorrogação e ampliação da política de fundos, que dessem conta de superar os problemas não alcançados pela Lei 9.424/1996 ao mesmo tempo que avançassem na correção dos graves problemas educacionais do país (ARELARO, 2004; DAVIES, 2005). Entretanto, apesar dessa intenção, a proposta de emenda constitucional $n^{\circ} 415$, expedida pelo governo federal em 12 de maio de 2005, que propunha o que viria a ser o FUNDEB, era contraditória e caracterizada por uma forte presença de resquícios das políticas neoliberais dos anos de 1990, conforme aponta Arelaro (2004), sendo muito mais um "remendo", nas palavras de Nicholas Davies (2005), do que propriamente uma proposição nova.

Assim, foi aprovada em 19 de dezembro de 2006 a Emenda Constitucional $n^{\circ} 53$, que deu nova redação aos Arts. $7^{\circ}, 23,30,206,208,211$ e 212 da Constituição Federal de 1988 e ao Art. 60 do ADCT. A subvinculação de recursos constitucionais, que antes destinava-se apenas ao ensino fundamental, foi ampliada para a manutenção e desenvolvimento da educação básica. A Medida Provisória $\mathrm{n}^{\circ} 339$, de 28 de dezembro de 2006, implantou o FUNDEB compulsoriamente em todos os 26 estados e no Distrito Federal a partir de $1^{\circ}$ de janeiro de 2007.

Basicamente, as diferenças entre o FUNDEF e o FUNDEB se encontram no campo de abrangência dos fundos. Enquanto o FUNDEF era específico para o Ensino Fundamental, o FUNDEB contempla a educação infantil, anos iniciais e finais do Ensino Fundamental urbano e rural, Ensino Médio urbano e rural, Ensino Médio profissionalizante, Educação de Jovens e Adultos, Educação Especial, Educação Indígena e de Quilombolas. Além da abrangência, o FUNDEB trouxe um maior detalhamento de pontos sobre a operacionalização da redistribuição de recursos do fundo, cálculo do número das matrículas para o repasse e uma melhor definição para o componente do padrão mínimo de qualidade (BRAGA, 2015). Outro elemento a ser considerado é a ampliação do texto legal no campo da valorização dos trabalhadores em educação para os demais profissionais da educação escolar.

Ao analisar as perspectivas perpassadas, do FUNDEF ao FUNDEB, é possível perceber novas configurações inerentes à evolução dos fundos. A Lei $n^{\circ} 11.494$, de 20 de junho de 2007, que regulamenta o FUNDEB, delibera sobre todos os aspectos da composição e organização do fundo. Dentre as alterações previstas de um fundo para outro, destacam-se as determinações dos percentuais aplicados. Enquanto no FUNDEF a subvinculação era de $15 \%$ das receitas para o ensino fundamental, uma das especificidades do FUNDEB é a subvinculação de $20 \%$, abrangendo, a partir da sua instituição, toda a educação básica, ou seja, a Educação Infantil e o Ensino Médio. Essas etapas da educação básica, a partir de então, passam a ser incluídas na agenda pública, como prioridade de atendimento e 
investimentos. Além disso, segundo a lei do FUNDEB, novos recursos passariam a compor o fundo. Os estados, além dos $20 \%$ de recursos já previstos no FUNDEF do FPE e da Cota Estadual do IPI-Exportação, comporiam também $20 \%$ de seus impostos próprios: ICMS, ITCMD e IPVA. Os municípios, além de recursos já previstos no FUNDEF, 20\% do FPM, Cota Parte do ICMS e IPI-Exportação, contribuiriam com o fundo com $20 \%$ da Cota Parte Municipal do IPVA, ITR. Compõe também o FUNDEB os recursos da Lei Kandir.

O aumento do percentual da subvinculação, assim como o aporte de novos recursos, foi positivo no sentido de ampliar a capacidade do FUNDEB. Entretanto, a literatura aponta que essa política teve um efeito duplo. A entrada do ICMS na cesta de recursos fez com que municípios com maior receita de ICMS transferissem recursos para os de menor receita, acentuando o caráter redistributivo do fundo (PINTO, 2007). Porém, as características das políticas de fundo têm um efeito inverso, que atinge especialmente os municípios menores de regiões mais pobres, cuja principal fonte de receitas vem das transferências da União via FPM. 94\% dos municípios com população menor que 2 mil habitantes e 72,5\% de municípios entre 2 e 5 mil habitantes perderam recursos com o FUNDEF (BREMAEKER, 2011), medida que tendeu a se acentuar com o FUNDEB.

Esta seção da pesquisa procurou evidenciar os processos de formulação e implementação das políticas de fundo, assim como suas configurações normativas. Com a aproximação do fim da vigência dessa lei, se torna necessário avaliar empiricamente as repercussões do FUNDEB nos municípios. Dessa maneira, passamos agora a analisar os dados orçamentários dos municípios mineiros, a arrecadação própria e advinda de transferências constitucionais obrigatórias. Analisar-se-á também os recursos destinados para a composição do FUNDEB e os recebidos a partir do número de matrículas.

\section{O FUNDEB no Financiamento da Educação em Municípios Mineiros}

Os dados orçamentários de 2017 dos municípios mineiros foram obtidos no site da Secretaria do Tesouro Nacional da base Finanças do Brasil (FINBRA/STN). A base FINBRA é um banco de dados criado pela Secretaria do Tesouro Nacional e apresenta números consolidados de estados e municípios brasileiros. A coleta é feita por meio de declaração dos próprios municípios que respondem, anualmente, a um formulário denominado Quadro de Dados Contábeis Consolidados (QDCC), com informações extraídas do seu balanço. Em virtude dessa natureza autodeclaratória, alguns dados não são informados e/ou apresentam erros de preenchimento. Dessa forma, por evidentes incoerências, foram retirados da análise os municípios de Bom Jesus da Penha, Carvalhópolis, Coqueiral, Divisópolis, Luz, Piranga, Ritápolis e Wanceslau Braz. Apesar da presença de inconsistências, a opção por essa fonte de dados se justifica pela sua abrangência espacial e temporal.

O estado de Minas Gerais apresenta grande desigualdade em relação à arrecadação tributária, sendo que os 20 municípios com maior poder de arrecadação respondem por $38,82 \%$ do total de receitas. Costuma-se apontar o estado como um espelho do Brasil, uma vez que a concentração de riquezas (e os bolsões de pobreza) pode ser claramente percebida geograficamente (Figura 1). Os municípios com maiores receitas concentram-se no entorno da capital, na Região Metropolitana de Belo Horizonte e no triângulo mineiro. Nas demais regiões, alguns poucos municípios se destacam, sendo por isso denominados de capitais 
Repercussões do FUNDEB em Municípios Mineiros

regionais. A pobreza está concentrada no Norte, no vale do Jequitinhonha, no Campo das Vertentes e no Sul do estado.

Figura 1 - Municípios de Minas Gerais quanto à distribuição da arrecadação de Impostos Próprios e Transferências Constitucionais, 2017

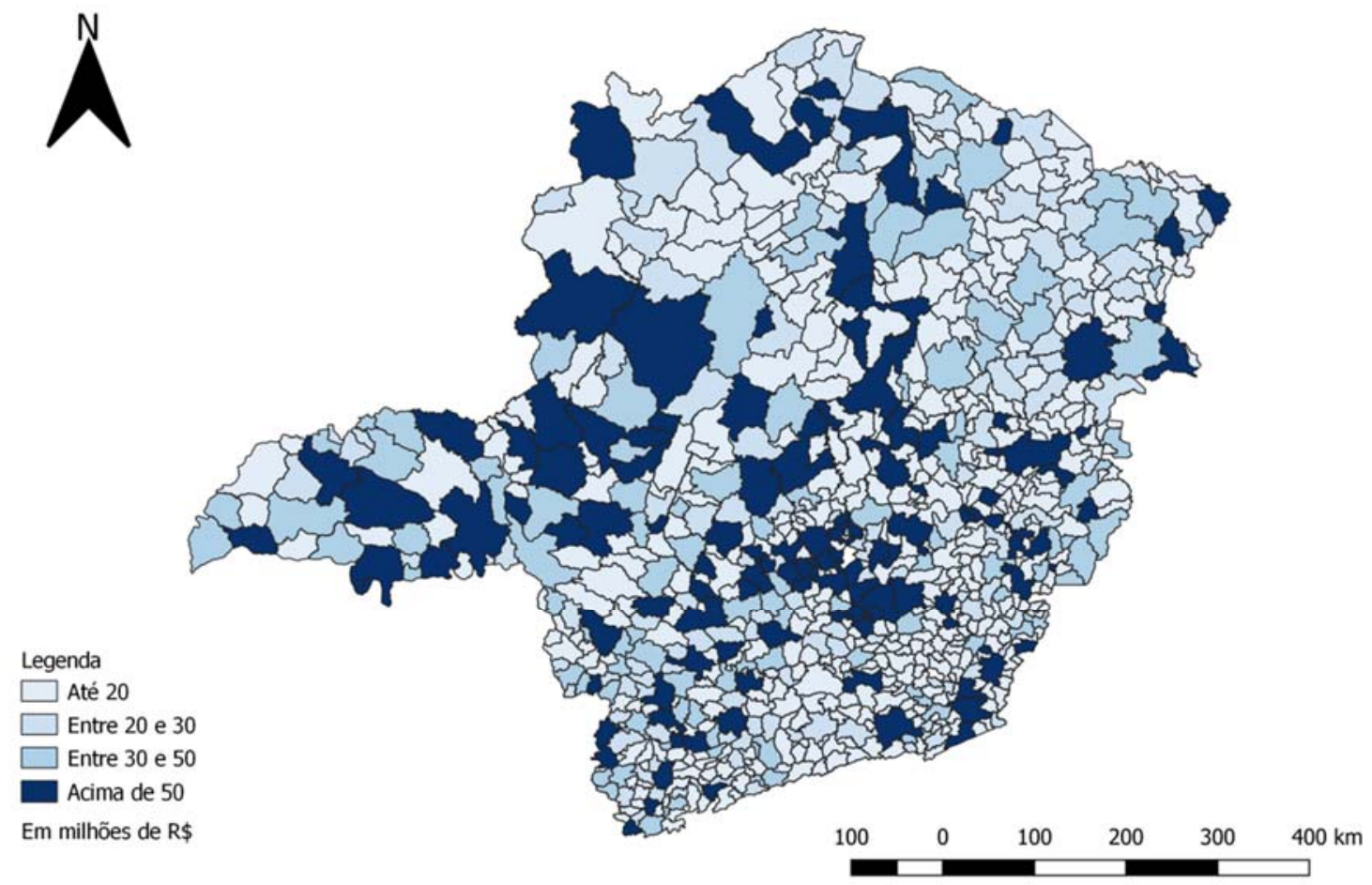

Fonte: Elaboração própria a partir de dados da base FINBRA/STN (2017).

Dadas as características demográficas do estado, é necessário se avaliar a arrecadação em relação ao número de estudantes regularmente matriculados (custo aluno ano). Para o cálculo do que cada município teria disponível no ano de 2017 por estudante foram divididos os valores de receitas constitucionalmente vinculadas (Impostos Próprios e Transferências Constitucionais Obrigatórias, assim como multas, juros de mora e receitas provenientes dessas fontes) e os recursos advindos do FUNDEB pelo número de matrículas de responsabilidade do município. Os dados das matrículas foram extraídos do Censo Escolar, realizado anualmente pelo Instituto Nacional de Pesquisas Educacionais Anísio Teixeira (INEP). Para fins de análise, foram consideradas as matrículas atendidas pela dependência administrativa municipal em sua competência legal, i.e. Educação Infantil e Ensino Fundamental. Tomou-se cuidado de inserir no cálculo as matrículas da Educação de Jovens e Adultos do município, quando existentes.

Fazendo-se um exercício de comparação, em um cenário no qual não existisse o FUNDEB e as prefeituras contassem apenas com seus recursos próprios e advindos das transferências constitucionais obrigatórias, ainda que a maioria (830) dos municípios analisados tivessem recursos acima do valor/aluno ano previsto para 2017 (R\$2.875,03), o 
cenário da desigualdade da capacidade institucional de atendimento (DUARTE; FARIA, 2010) seria significativamente alto, conforme pode ser visto na Tabela 1.

Tabela 1 - Estatísticas descritivas dos recursos p/aluno de municípios mineiros em cenário hipotético sem o FUNDEB, 2017

\begin{tabular}{lr}
\hline Medida descritiva & Estatística \\
\hline Média & $6.912,35$ \\
$5 \%$ da média aparada & $6.343,23$ \\
Mediana & $5.917,95$ \\
Desvio Padrão & $5.352,82$ \\
Coeficiente de Variação & $77,43 \%$ \\
Amplitude interquartil & $2.967,16$ \\
\hline
\end{tabular}

Fonte: Elaboração própria a partir de dados da base FINBRA/STN (2017).

Os valores extremos são resultantes de um complexo contexto, em que coexistem no estado municípios com poucas matrículas e alta arrecadação tributária (como é o caso de algumas cidades mineradoras); e municípios com grande número de matrículas e atividade econômica limitada, como municípios no entorno de polos regionais (também chamadas 'cidades dormitório'). A título de exemplos, nos dados de 2017 se destacam, em um extremo, municípios como Douradoquara (população estimada em 1.841 habitantes e 31 matrículas na rede municipal, $R \$ 107.891,02$ p/aluno), Grupiara (população estimada em 1.433 habitantes e 48 matrículas na rede municipal, $\mathrm{R} \$ 68.767,35$ p/aluno) e Itambé do Mato Dentro (população estimada em 2.434 habitantes e 89 matrículas na rede municipal, $R \$ 34.662,68$ p/aluno), todas cidades localizadas em regiões mineradoras. No outro extremo, podemos divisar Esmeraldas (população estimada em 66.237 habitantes e 8.672 matrículas, $R \$ 2.147,95$ p/aluno), Sabará (população estimada em 135.196 e 13.924 matrículas, $R \$ 2.691,24$ p/aluno) e Ribeirão das Neves (população estimada em 328.871 habitantes e 23.051 matrículas, R\$ 2.431,31 p/aluno), todos na Região Metropolitana de Belo Horizonte.

Os dados apontam que a utilização da mediana é mais adequada para a análise devido a sua assimetria e uma vez que os valores outliers elevam a média. A grande amplitude interquartil também indica que, em um contexto sem o FUNDEB, os $25 \%$ dos municípios com menor arrecadação estariam muito distantes dos $25 \%$ dos municípios com maior poder arrecadatório. Graficamente, essas informações podem ser ilustradas por meio de sua dispersão, em que cada município representa uma marcação. A Figura 2 nos permite visualizar o alto coeficiente de variação $(77,43 \%)$ das receitas vinculadas por aluno. 
Figura 2 - Gráfico de dispersão das receitas vinculadas sem FUNDEB por aluno em municípios mineiros, 2017

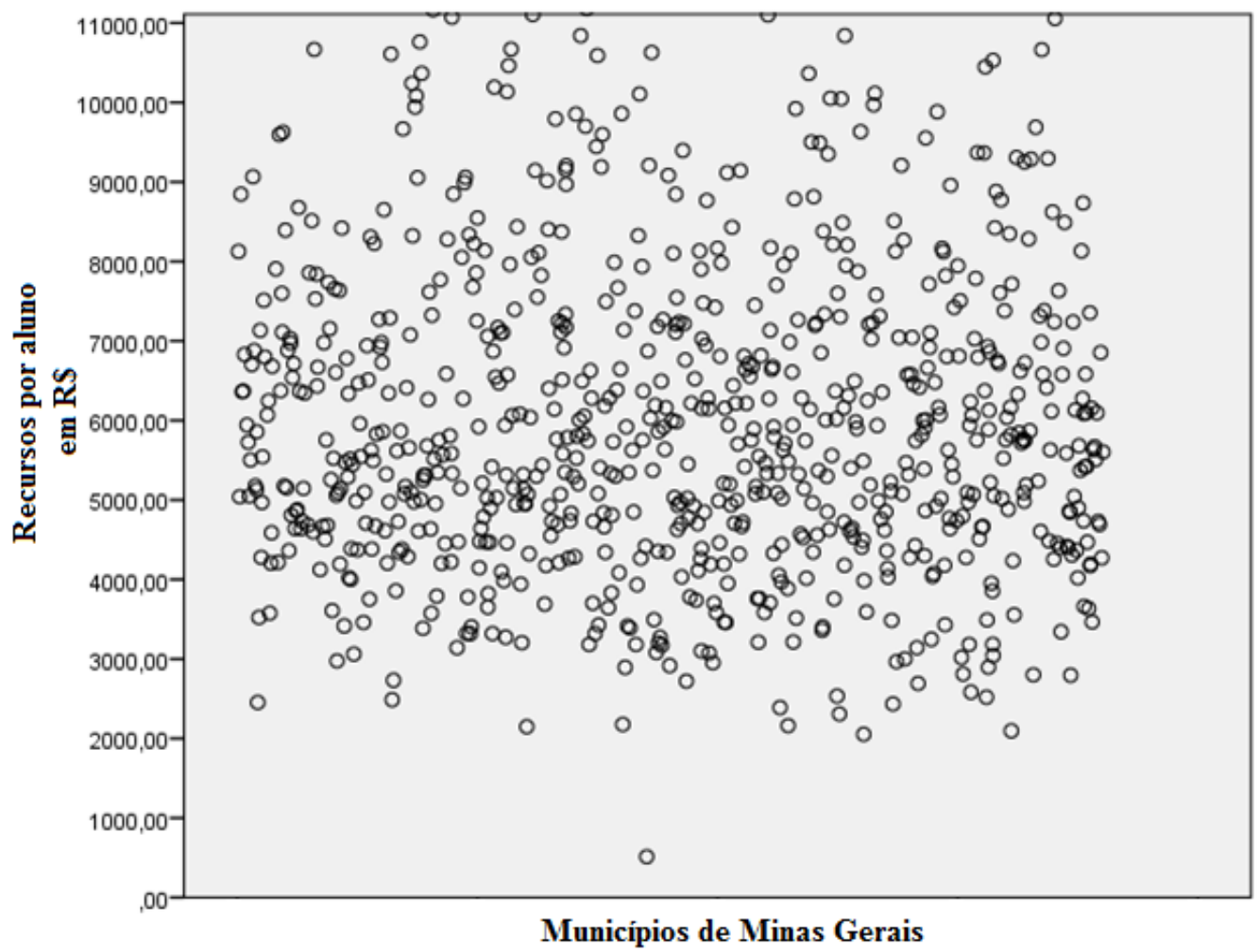

Fonte: Elaboração própria a partir de dados da base FINBRA/STN (2017).

Quando se leva em conta o FUNDEB, os números revelam que o fundo teve um importante fator redistributivo de recursos. Conforme a literatura aponta, ainda que a política de fundos não traga recursos novos (ARELARO, 2004; DAVIES, 2005), ela favorece a diminuição das desigualdades dentro dos estados. A Tabela 2 traz informações estatísticas de medidas de tendência central dos dados de receita orçamentária por aluno em Minas Gerais para o ano de 2017. De acordo com os dados, é possível ver que a média se reduz - uma vez que municípios com muita arrecadação e poucos alunos matriculados perdem recursos, que são redistribuídos entre os municípios com mais alunos matriculados.

Tabela 2 - Estatísticas descritivas dos recursos p/aluno de municípios mineiros com o FUNDEB, 2017

\begin{tabular}{lr}
\hline Medida descritiva & Estatística \\
\hline Média & $5.075,46$ \\
$5 \%$ da média aparada & $4.978,90$ \\
Mediana & $4.771,48$ \\
Desvio Padrão & $1.428,35$ \\
Coeficiente de Variação & $28,14 \%$ \\
Amplitude interquartil & 952,86 \\
\hline \multicolumn{2}{c}{ Fonte: Elaboração própria a partir de dados da base FINBRA/STN (2017). }
\end{tabular}

Quando o FUNDEB é considerado, o coeficiente de variação se reduz em quase 50 pontos percentuais, o que evidencia diminuição da variação em torno da média. Essa informação pode ser mais bem observada através da sua dispersão (Figura 3). A amplitude interquartil também se reduz consideravelmente, o que significa a diminuição da distância entre o grupo dos municípios mais ricos e os mais pobres. 
Figura 3 - Gráfico de dispersão das receitas vinculadas e recursos do FUNDEB por aluno em municípios mineiros, 2017

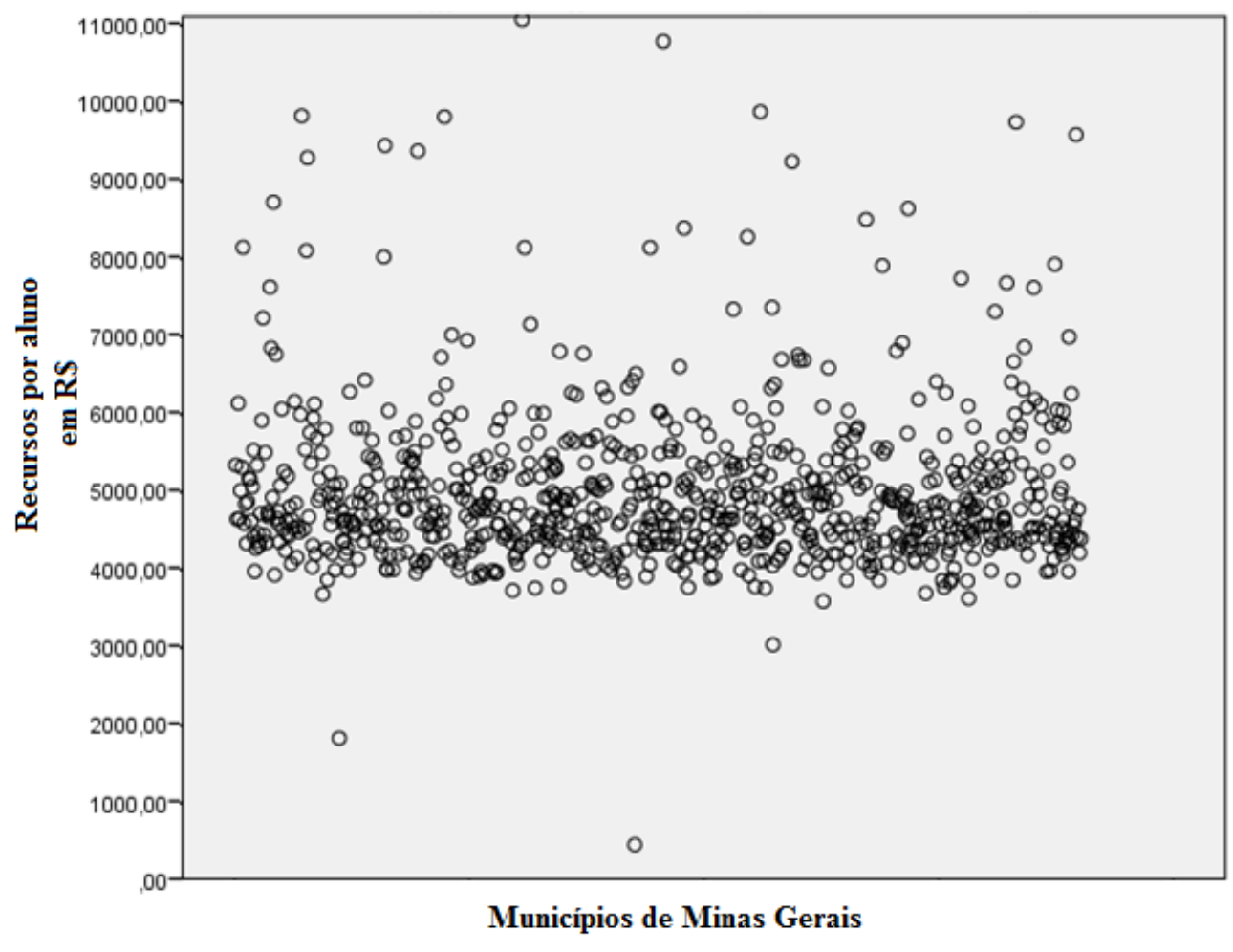

Fonte: Elaboração própria a partir de dados da base FINBRA/STN (2017).

Os diagramas de caixa (boxplot) da Figura 4 complementam as análises da dispersão dos recursos por aluno em cenários sem e com a política de fundos. Percebe-se que o FUNDEB tem efeito distributivo, uma vez que concentra os dados em torno da média. $75 \%$ dos municípios com o fundo têm receitas que estariam inteiramente no primeiro quartil em um cenário sem FUNDEB. Além disso, os diagramas permitem analisar que os municípios com arrecadação alta (seja a própria e as transferências constitucionais não-subvinculadas, $5 \%$ ) mantêm recursos maiores - apesar das perdas com o fundo. Os valores outliers, apesar da redução significativa, continuam se referindo aos mesmos municípios, evidenciando que a política de fundos redistribui recursos garantindo um valor médio estadual por aluno, sem, no entanto, descaracterizar as diferenças entre os municípios mais ricos (no caso, com mais recursos por aluno). 
Figura 4 - Gráfico de medidas de posição dos recursos por aluno em municípios mineiros, 2017

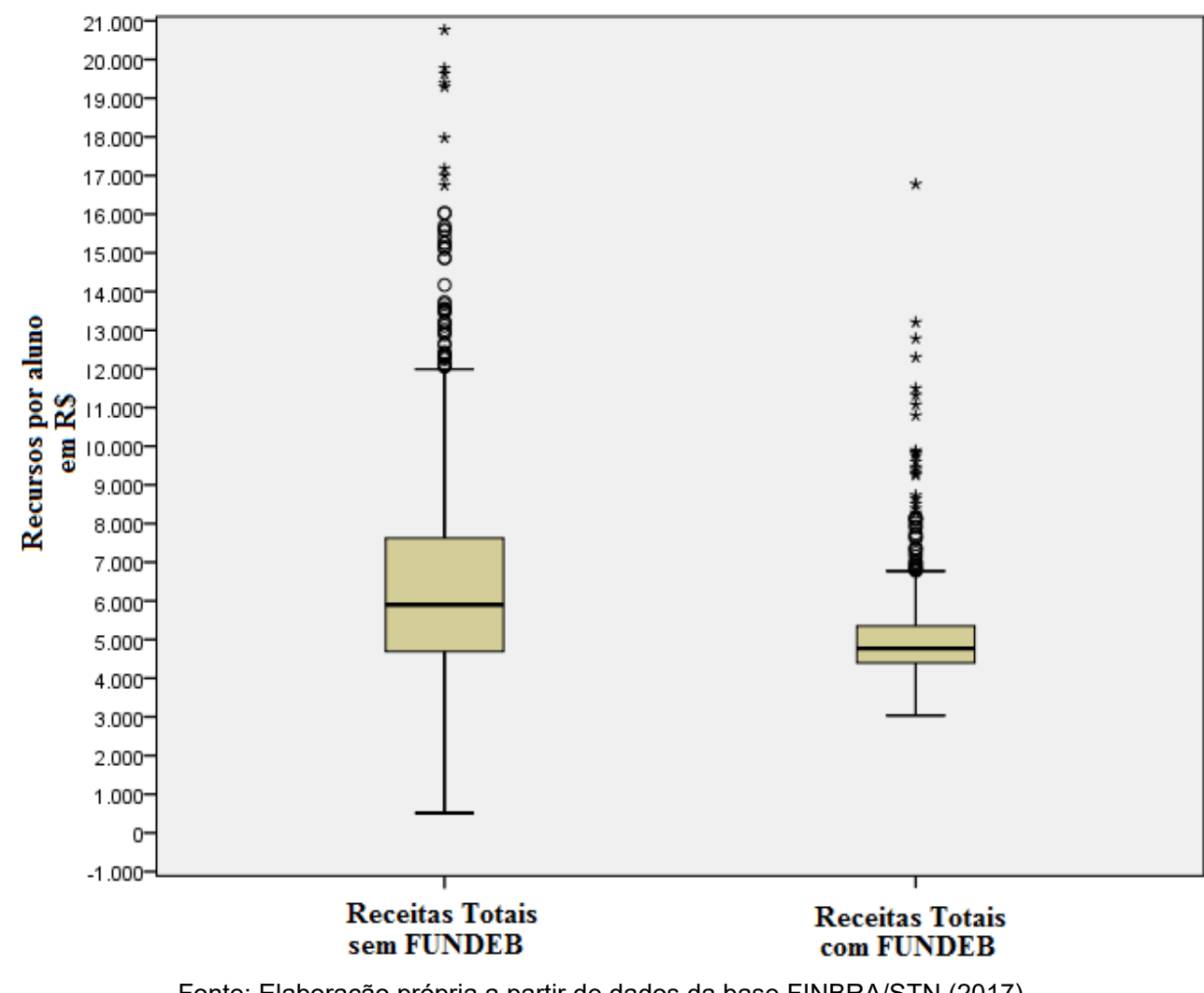

Os dados de Minas Gerais para 2017 também confirmam as projeções da literatura (BRAEMAEKER, 2011; PINTO, 2014), que apontaram que a ampliação do escopo de abrangência do Ensino Fundamental no FUNDEF para a Educação Infantil e o Ensino Médio no FUNDEB impactaria negativamente os municípios mais pobres e com poucos estudantes em suas etapas de atendimento de competência constitucional. Isso ocorre porque alguns desses municípios têm perdas de recurso com o fundo que são destinados aos alunos matriculados no Ensino Médio, que está majoritariamente sob responsabilidade jurisdicional da administração pública estadual.

Ao se contrastar o gráfico de dispersão de um hipotético cenário sem o FUNDEB (Figura 2) com o gráfico da dispersão em contexto de FUNDEB, é possível afirmar que, ainda que os valores médios e a mediana tenham diminuído, as desigualdades dentro de Minas Gerais também foram reduzidas no tocante ao montante de recursos por aluno. A fim de verificar a distribuição geográfica dessa redução, foram elaborados dois mapas com variação de graduação do valor por aluno sem e com o FUNDEB (Figura 5). Quanto mais escuro o município aparece representado nos mapas, maior o recurso por aluno. 
Repercussões do FUNDEB em Municípios Mineiros

Figura 5 - Mapa dos municípios mineiros em relação ao valor por aluno no cenário hipotético sem FUNDEB e no contexto de FUNDEB, 2017

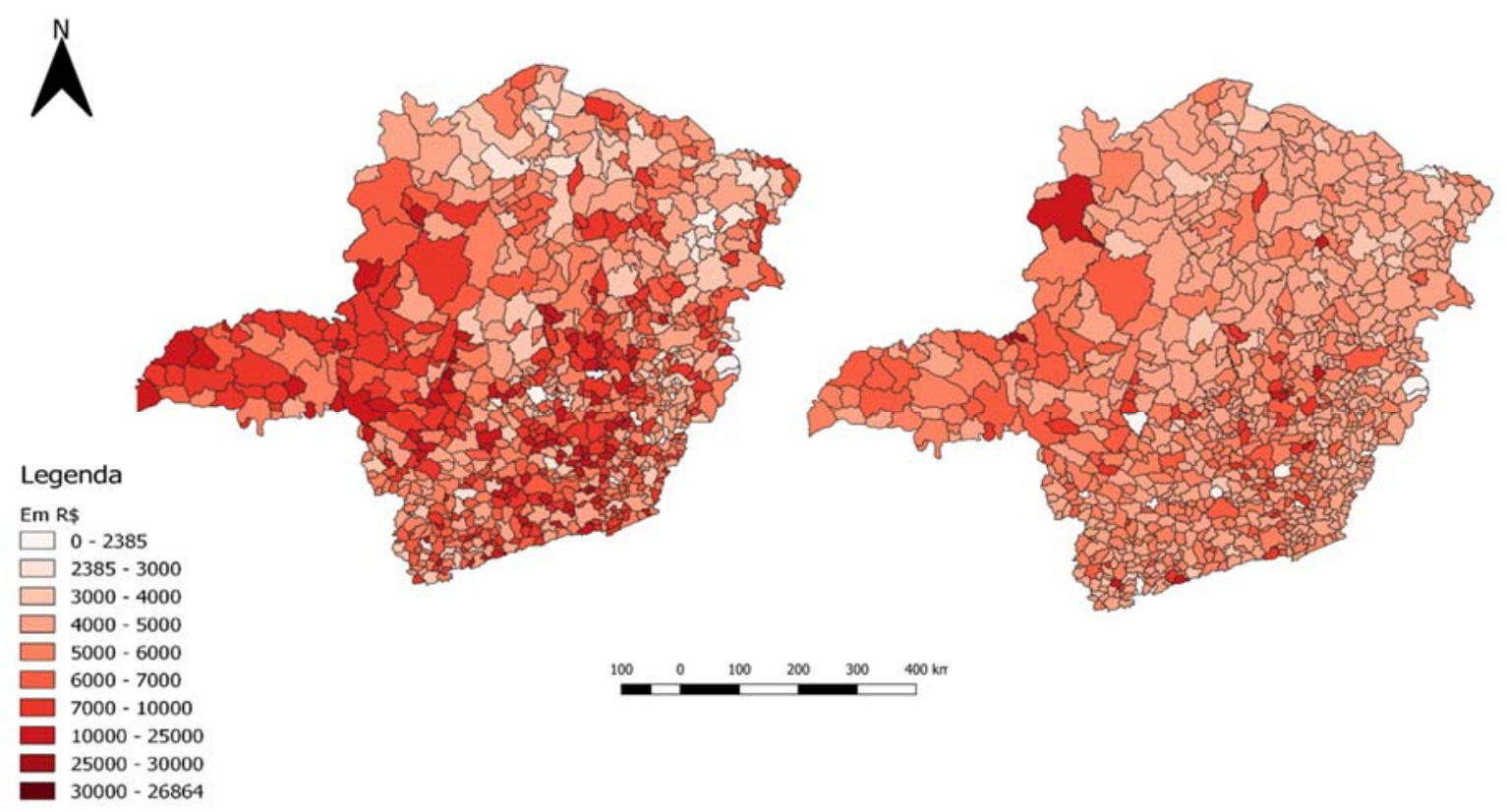

Fonte: Elaboração própria a partir de dados da base FINBRA/STN, 2017.

Os mapas permitem enxergar o efeito do FUNDEB na redistribuição geográfica de recursos por aluno conforme os dados evidenciaram. Em comparação com o mapa da Figura 1 da arrecadação própria dos municípios em Minas Gerais, os recursos por aluno em um contexto sem FUNDEB acompanham o montante total dos municípios mais ricos, além de incluir na tonalidade mais escura os municípios com alto poder arrecadatório e pequeno número de alunos matriculados. Destacam-se nesse cenário hipotético os municípios da Região Metropolitana, Central mineira e Triângulo (desta, mais especificamente a região do Alto Paranaíba). Entretanto, quando o FUNDEB é considerado, a distribuição de recursos no mapa tem sua desigualdade diminuída, como se pode ver na redução das tonalidades escuras. As exceções mais nítidas são Unaí, no Noroeste, e as já referidas Douradoquara e Grupiara, no triângulo, que ficam com a tonalidade mais escura no contexto do FUNDEB.

\section{Considerações Finais}

A aproximação de encerramento da vigência do FUNDEB em 2020, associada às questões suscitadas pelo Plano Nacional de Educação e a concorrência da necessidade de ampliação de recursos para o cumprimento desse plano com as limitações ocasionadas pela Emenda Constitucional $n^{\circ} 95$ de 2016, levantaram sérias dúvidas a respeito da viabilidade futura do financiamento da educação. Os municípios, alçados a entes federados pela CF/88 e detentores da responsabilidade da oferta de vagas da educação básica por essa mesma Constituição, são também o elo mais fraco do sistema fiscal e tributário brasileiro, e, em sua grande maioria, extremamente dependentes de transferências constitucionais para seu funcionamento mínimo, assim como para a oferta de serviços educacionais à população. Portanto, os municípios são os mais interessados na elaboração de instrumentos de políticas públicas mais perenes que garantam recursos mínimos para uma educação de qualidade. 
As análises realizadas por esta pesquisa, acerca da real necessidade do FUNDEB como política de financiamento da Educação, dialogam com a literatura sobre o tema, corroborando com ela. As informações sobre os recursos vinculados à manutenção e desenvolvimento do ensino revelam disparidades de capacidade de investimento em educação, resultado de desigualdades econômicas intraestaduais. Os esforços de raciocínio com simulação de um cenário hipotético, sem a presença do FUNDEB, em comparação com a realidade empírica dos efeitos do fundo de financiamento para os municípios mineiros, alargam o olhar sobre a capacidade institucional de atendimento em educação presentes na federação e a injustiça tributária do País.

Este exercício revelou que, sem o FUNDEB, a maioria dos municípios mineiros conseguiria atingir o patamar mínimo de recursos por aluno, entretanto, o fundo tem cumprido um importante efeito redistributivo, uma vez que torna, pelo menos quanto ao montante de recursos por aluno, o estado mais homogêneo, diminuindo desigualdades regionais. $\mathrm{O}$ fato de a União não colocar recursos novos no cesto para a educação, na prática diminui a média e a mediana do valor aluno ano por município, pois passam a dividir recursos com as matrículas estaduais do Ensino Médio. Mesmo com a tendência à homogeneização, as desigualdades no financiamento da educação e a existência de cidades mineiras com alta capacidade institucional de investir em educação, enquanto outras têm a capacidade limitada, ainda são bastante nítidas, como os dados revelaram.

Em síntese, dada a iminência do fim do FUNDEB, os dados desta pesquisa apontam para a necessidade da manutenção dessa política de fundo de financiamento, uma vez que ela tem cumprido seu papel de diminuir graves distorções e desigualdades de acesso a recursos por aluno. A análise dos dados confirma ainda as considerações de ampla literatura sobre o tema, que discute a limitação do desenho do FUNDEB, especialmente no tocante ao papel da União na complementação de recursos, a fim de se atingirem novos (e mais elevados) patamares mínimos por aluno. Dessa forma, seria possível garantir, ao mesmo tempo, diminuição de desigualdades regionais e ampliação de recursos para a efetivação do preceito constitucional de educação de qualidade.

\section{Referências}

ABREU, Mariza. Estudo sobre as possibilidades de continuidade do FUNDEF e o financiamento da educação básica no país. Brasília: Câmara dos Deputados; Consultoria do Legislativo, maio 2003. Disponível em: <http://www2.camara.leg.br/a-camara/documentose-pesquisa/estudos-e-notas-tecnicas/arquivos-pdf/pdf/303954.pdf>. Acesso em: 30 jun. 2018.

ABRUCIO, Fernando Luiz. A coordenação federativa no Brasil: a experiência do período FHC e os desafios do governo Lula. Revista de Sociologia e Política, Curitiba, n. 24, p. 41-67, jun. 2005.

ARELARO, Lisete. Os fundos públicos no financiamento da educação - o caso Fundeb: justiça social, equívoco político ou estratégia neoliberal? 2004. Tese (Livre Docência em Política e Organização da Educação Básica I e II) - Faculdade de Educação, Universidade de São Paulo, set. 2004. 
Repercussões do FUNDEB em Municípios Mineiros

ARELARO, Lisete. Fundef: uma avaliação preliminar dos dez anos de sua implantação. In: REUNIÃO ANUAL DA ANPED, 30., 2007, Caxambu. Anais... Caxambu, 2007. Disponível em: <http://www.anped.org.br/reunioes/30ra/index.htm>. Acesso em: 30 jun. 2018.

BRAGA, Daniel S. Limites e possibilidades das políticas públicas de financiamento da educação: os impactos dos fundos de manutenção e desenvolvimento na valorização de professores em Minas Gerais (1996-2012). 2015. 111 f. Dissertação (Mestrado em Educação) - Faculdade de Educação, Universidade do Estado de Minas Gerais, Belo Horizonte, 2015.

BRASIL. Constituição Federal de 1988. Promulgada em 5 de outubro de 1988. Diário Oficial da União, Brasília, 1988. Disponível em <http://www.planalto.gov.br/ccivil_03/constituicao/ constituição.htm>. Acesso em: 30 de junho 2018.

BRASIL. Emenda Constitucional no 14, de 12 de setembro de 1996. Modifica os arts. 34, 208, 211 e 212 da Constituição Federal e dá nova redação ao art. 60 do Ato das Disposições Constitucionais Transitórias. Diário Oficial da União, Brasília, 13 set. 1996a. Disponível em: <http://www.planalto.gov.br>. Acesso em: 30 jun. 2018.

BRASIL. Lei 9.424, de 24 de dezembro de 1996. Dispõe sobre o Fundo de Manutenção e Desenvolvimento do Ensino Fundamental e de Valorização do Magistério, na forma prevista no art. $60, \S 7^{\circ}$, do Ato das Disposições Constitucionais Transitórias, e dá outras providências. Diário Oficial da União, Brasília, 26 dez. 1996b. Disponível em: <http://www.planalto.gov.br/ ccivil_03/LEIS/L9424.htm>. Acesso em: 30 jun. 2018.

BRASIL. Lei no 11.494, de 20 de junho de 2007. Regulamenta o Fundo de Manutenção e Desenvolvimento da Educação Básica e de Valorização dos Profissionais da Educação FUNDEB, de que trata o art. 60 do Ato das Disposições Constitucionais Transitórias. Diário Oficial da União, Brasília, 21 jun. 2007. Disponível em: <http://www.planalto.gov.br/ ccivil_03/_ato2007-2010/2007/lei/l11494.htm>. Acesso em: 30 jun. 2018.

BREMAEKER, François E. J. A política de fundos para a educação e o impacto nas finanças dos Estados e municípios. In: GOUVEIA, Andréa B.; PINTO, José Marcelino R.; CORBUCCI, Paulo Roberto (Org.). Federalismo e políticas educacionais na efetivação do direito à educação no Brasil. Brasília, DF: Ipea, 2011. p. 51-68.

DAVIES, Nicholas. Fundos para o financiamento da educação: solução ou remendo? Caderno de debates, São Paulo, n. 2, p. 23-29, nov. 2005.

DUARTE, Marisa Ribeiro Teixeira.; FARIA, Geniana Guimarães. Recursos públicos para escolas públicas: as políticas de financiamento da Educação Básica no Brasil e a regulação do Sistema Educacional Federativo. Belo Horizonte: RHJ/FAE da UFMG, 2010.

FARENZENA, Nalú. A política de financiamento da educação básica: rumos da legislação brasileira. Porto Alegre: editora UFRGS, 2006.

FLEURY, Sonia. Verbete: Políticas Sociais. In: OLIVEIRA, Dalila Andrade; DUARTE, Adriana Maria Cancella; VIEIRA, Lívia Fraga. DICIONÁRIO: trabalho, profissão e condição docente. Belo Horizonte: UFMG, Faculdade de Educação, 2010.

NEGRI, Barjas. O fundo de manutenção e desenvolvimento do ensino fundamental e de valorização do magistério. Brasília: INEP, 1997. 
Repercussões do FUNDEB em Municípios Mineiros

OLIVEIRA, Cleiton de et al. Municipalização do Ensino no Brasil. Belo Horizonte: Autêntica, 1999. v. 1. $128 p$

OLIVEIRA, Romualdo Portela de. A municipalização cumpriu suas promessas de democratização da gestão educacional? um balanço crítico. Gestão em Ação, Salvador, v. 6, n. 2, p. 99-106, jul./dez. 2003.

PINTO, José Marcelino Rezende. Os Recursos para Educação no Brasil no Contexto das Finanças Públicas. São Paulo: Ed. Plano, 2000.

PINTO, José Marcelino Rezende. Federalismo, descentralização e planejamento da educação: desafios aos municípios. Cadernos de Pesquisa, São Paulo, v. 44, n. 153, p. 624644, 2014.

REIS, Bruno Pinheiro W. Verbete: Políticas Públicas. In: OLIVEIRA, Dalila Andrade; DUARTE, Adriana Maria Cancella; VIEIRA, Lívia Fraga. DICIONÁRIO: trabalho, profissão e condição docente. Belo Horizonte: UFMG; Faculdade de Educação, 2010.

Daniel Santos Braga é professor no Centro Universitário Newton Paiva. Doutorando, em Educação: Conhecimento e Inclusão Social, pela Universidade Federal de Minas Gerais. Mestre em Educação e Formação Humana pela Universidade do Estado de Minas Gerais, com pesquisa na área do Financiamento Público da Educação e a Valorização do Magistério. Graduado em Pedagogia e História. Possui experiência docente e como coordenador pedagógico na educação básica na Rede Estadual de Minas Gerais e na Prefeitura de Belo Horizonte.

ORCID: http://orcid.org/0000-0001-5075-4570

E-mail: danielsantosbraga@gmail.com

Débora Cristina Alves da Silva atualmente cursa Pedagogia na Universidade Federal de Minas Gerais. Também graduada em História na modalidade licenciatura pela Universidade Federal de Minas Gerais (2014). Durante o primeiro semestre de 2013 foi intercambista na Universidade de Évora (Portugal). Foi bolsista CNPq no projeto Política e Administração de Sistemas Educacionais.

ORCID: http://orcid.org/0000-0003-2849-6733

E-mail: debora.cristina542@gmail.com 


\section{Editores do volume 9}

José Marcelino de Rezende Pinto - Universidade de São Paulo, São Paulo/SP, Brasil

Nalú Farenzena - Universidade Federal do Rio Grande do Sul, Porto Alegre/RS, Brasil

\section{Comitê Editorial}

José Marcelino de Rezende Pinto - Universidade de São Paulo, Brasil

Juca Gil - Universidade Federal do Rio Grande do Sul, Brasil

Theresa Adrião - Universidade Estadual de Campinas, Brasil Ângelo

Ricardo de Souza - Universidade Federal do Paraná, Brasil

Márcia Aparecida Jacomini - Universidade Federal de São Paulo, Brasil

\section{Conselho Editorial}

\section{Alejandro Morduchowicz}

Universidad Pedagógica, Provincia de Buenos Aires, Argentina

Fernanda Saforcada

Universidade de Buenos Aires, Argentina

Jacques Velloso

Universidade de Brasília, Brasil

João Monlevade

Senado Federal, Brasil

Jorge Abrahão de Castro

Instituto de Pesquisa Econômica Aplicada / IPEA, Brasil

Juca Gil

Universidade Federal do Rio Grande do Sul, Brasil

Lisete Regina Gomes Arelaro

Universidade de São Paulo, Brasil

Luis Carlos Sales

Universidade Federal do Piauí, Brasil

Luiz de Sousa Junior

Universidade Federal da Paraíba, Brasil

Luiz Fernandes Dourado

Universidade Federal de Goiás, Brasil

Magna França

Universidade Federal do Rio Grande do Norte, Brasil

\section{Maria Beatriz Luce}

Universidade Federal do Pampa, Brasil

Universidade Federal do Rio Grande do Sul, Brasil

Marcos Edgar Bassi

Universidade Federal de Santa Catarina, Brasil

\author{
Maria Dilnéia Espíndola Fernandes \\ Universidade Federal de Mato Grosso do Sul, Brasil \\ Nalú Farenzena \\ Universidade Federal do Rio Grande do Sul, Brasil \\ Nelson Cardoso do Amaral \\ Universidade Federal de Goiás, Brasil \\ Nicholas Davies \\ Universidade Federal Fluminense, Brasil \\ Rosana Evangelista Cruz \\ Universidade Federal do Piauí, Brasil \\ Rosana Gemaque \\ Universidade Federal do Pará, Brasil \\ Robert E. Verhine \\ Universidade Federal da Bahia, Brasil \\ Romualdo Portela de Oliveira \\ Universidade de São Paulo, Brasil \\ Theresa Adrião \\ Universidade Estadual de Campinas, Brasil \\ Tristan McCowan \\ University of London, Reino Unido \\ Vera Jacob \\ Universidade Federal do Pará, Brasil \\ Vera Peroni \\ Universidade Federal do Rio Grande do Sul, Brasil \\ Vitor Henrique Paro \\ Universidade de São Paulo, Brasil
}

\section{Equipe editorial}

Apoio ao Comitê Editorial: Patrícia Balthazar Garcia

Diagramação, Revisão de português e normalização: Edson Leonel de Oliveira

Revisão de inglês: Ananyr Porto Fajardo 